\title{
Suspected nasopharyngeal carcinoma in three workers with long term exposure to sulphuric acid vapour
}

\author{
Chi-Kung Ho, Wally C H Lo, Pei-Hsin Huang, Ming-Tsang Wu, David C Christiani, \\ Chin-Tang Lin
}

\begin{abstract}
Sulphuric acid vapour has been suspected of being an industrial carcinogen. In this study, a cluster is presented of three patients with nasopharyngeal carcinoma (NPC) who worked in the same building of a telecommunications conveyance station in southern Taiwan with long term exposure to sulphuric acid vapour concentrations as high as $0.18 \mathrm{mg} / \mathrm{m}^{3}$. All three workers were diagnosed with NPC within a 5 month period between September 1992, and March 1993. Compared with 19 other healthy workers from the same building, these three workers with NPC had worked significantly longer in this building than had the others (mean (SD) (years): 12.7 ( 0.6) $v 7.4$ (4.4); $\mathrm{p}=0.01)$. With an in situ nucleic acid hybridisation and immunostaining method for colocalised Epstein-Barr virus (EBV) and secretory component (SC) protein among biopsy specimens of these three patiente with NPCs, it was found that some tumour cells did not contain EBV and SC protein staining signals. These results indicate that EBV infection is not the only risk factor for NPC and long term exposure to relatively low concentrations of sulphuric acid vapour may be associated with the development of NPC.

(Occup Environ Med 1999;56:426-428)
\end{abstract}

Keywords: nasopharyngeal carcinoma; sulphuric acid vapour; Epstein-Barr virus

Sulphuric acid vapour is a suspected occupational carcinogen. ${ }^{1}$ Epidemiological studies have shown that prolonged exposure to sulphuric acid vapour is associated with the increase of various cancers, ${ }^{23}$ such as aerodigestive cancer and laryngeal cancer. In the current study, we present a cluster of three patients with nasopharyngeal cancer (NPC) who worked in the same telecommunications company with a high concentration of sulphuric acid vapour.

Dr C K Ho, Graduate Institute of Occupational Safety and Health,

Kaohsiung Medical College, Kaohsiung 807, Taiwan, Republic of China.

Accepted 18 December 1998

\section{Methods and results}

The study base comprised a telecommunication conveyance station, which is a 12 year old six floor building, in southern Taiwan. Thirty employees worked in this building in 1992-3. During the period from September 1992 to March 1993, three workers, aged 38, 39, and 52 and working in the same office on the sixth floor in this building were pathologically diagnosed with NPC.

The office on the sixth floor housed many functioning telecommunication cables and wires. Another room used for breaks, and with an area of $30 \mathrm{~m}^{2}$, was adjacent to this office. Directly below the rest area, there were two separate rooms on the fifth floor; one was full of lead sulphuric acid batteries and the other one was the power control room. Both rooms were built 3 years after the establishment of this building in 1980. A ventilation system had been installed in the battery room, and a hole of $100 \times 45 \mathrm{~cm}^{2}$ covered with wood was in the floor of the rest room on the sixth floor, and had been prepared to carry electric cables from the batteries. This hole was at the top of the wall which separated the battery room from the power control room on the fifth floor. The wooden rim of the hole was eroded and air could be felt flowing when the surrounding boards were lifted.

A walk through of the work site was initially carried out by an industrial hygienist for the determination of specific environment hazards. Subsequently, four fixed site area samplers were used to measure ambient sulphuric acid vapour around the hole on the sixth floor as well as in the power control room (two area samplers) and battery room on the fifth floor on 29 June, 6 September, and 7 September 1993. The samples were collected by charcoal tubes and analysed by a gas chromatography mass spectrometry with a detection limit of $0.004 \mathrm{mg} / \mathrm{m}^{3}$. The two highest concentrations of ambient sulphuric acid concentrations were $0.18 \mathrm{mg} / \mathrm{m}^{3}$, which occurred around the hole on the sixth floor on 29 June and 7 September 1993. The rest of the area samples were $<0.11$ $\mathrm{mg} / \mathrm{m}^{3}$.

We arranged a general health examination, especially a nasopharyngeal examination by an otolaryngologist for all people who worked in this building during July and August 1993. Including the three workers with NPC, a total 
Work information for three patients with nasopharyngeal carcinoma (NPC) and 19 healthy workers

\begin{tabular}{|c|c|c|c|}
\hline & $\begin{array}{l}N P C(n=3) \\
\text { Mean }(S D)\end{array}$ & $\begin{array}{l}\text { Controls }(n=19) \\
\text { Mean }(S D)\end{array}$ & $p$ Value * \\
\hline Age (y) & $43.7(7.2)$ & $38.4(6.3)$ & 0.18 \\
\hline $\begin{array}{l}\text { Duration of employment in the telecommunication } \\
\text { station }(y)\end{array}$ & $12.7(0.6)$ & $7.4(4.4)$ & 0.01 \\
\hline Duration of work in rest room on the 6 th floor $(\mathrm{h})$ & $2.0(1.0)$ & $0.3(0.6)$ & 0.003 \\
\hline
\end{tabular}

${ }^{\star}$ Non-parametric Mann-Whitney $U$ test.

of 22 workers completed the questionnaires about possible risk factors related to NPC. Detailed work histories including geographic distribution of daily working hours in this building, especially in the rest area of the sixth floor, were also collected from the three workers with NPC and another 19 healthy workers.

Compared with the other 19 healthy workers, the three workers with NPC had spent significantly more hours during the working day in the rest room of the sixth floor (mean (SD) $2.0(1.0) v 0.3(0.6)$ hours, $\mathrm{p}=0.003)$ and had worked significantly longer in this building than other workers (mean (SD) $12.7(0.6) v$ 7.4 (4.4) years, $\mathrm{p}=0.01$, table). There were no significant differences in their potential risk factors for NPC - such as burning incense, use of coal or charcoal, nasal ointment, pesticide, and antimosquito coils, medication, tobacco smoke, alcohol consumption, and family history of NPC (data not shown).

We reviewed the biopsy specimens from these three workers with NPC and two samples were of undifferentiated carcinoma and one was a non-keratinising squamous cell carcinoma (data not shown). To assess the relation between infection with Epstein-Barr virus (EBV) and the development of NPC among these three workers, we first checked EBVVCA antibody IgA titre in two of the workers with NPC (the third one refused a phlebotomy) and found a marked increase of IgA titre in one worker $(1: 1280)$, and a moderate increase in the other $(1: 160)$. With an in situ hybridisation of EBV encoded small nuclear RNA-1 (EBER-1) method to detect EBV signal of tumour cells in biopsy specimens, ${ }^{4}$ we found that some tumour cells were free of EBV. To confirm this finding, we then used a double localisation of EBER-1 and secretary component (SC) protein methods on the same paraffin section. ${ }^{5}$ The results remained the same; some tumour cells showed neither EBV signal nor SC protein staining.

\section{Discussion}

We present a cluster of three workers who had NPC who worked in the same office of one telecommunication conveyance station with lead sulphur acid batteries. Twelve years ago, the telecommunication company hired four people to work in the same area, and another 19 people worked in the same building but in different rooms. One year later, one of the four workers was transferred to another station 3 miles away and received no further exposure to acid vapour. $\mathrm{He}$ is still well at present. However, after the lead sulphuric acid battery room was set up on the fifth floor, the other three people worked continuously in this environment. Nine years later, all of them were diagnosed with NPC within a 5 month period. These findings suggested that NPC might be associated with occupational exposure to sulphuric acid vapour.

Epidemiological studies have shown some potential environmental risk factors for NPC, ${ }^{6}$ including consumption of salted fish, cigarette smoking, exposure to antimosquito coil smoke or incense smoke, consumption of preserved foods or fermented soy beans, and prescription of Chinese herbal medicine, nasal balm, and ointment. Based on our interview of personal risk factors for NPC by questionnaires among these study subjects, there were no significant differences between these three cases and other workers.

These three workers with NPC spent more time in the rest room on the sixth floor where the sulphuric acid concentration was the highest in this telecommunication station building. According to our walk through inspection, we found that the wooden frame was ruined after 9 years of exposure to the sulphuric acid vapour coming from the fifth floor through the hole in the rest room of the sixth floor due to incomplete sealing of the cover board. However, we did not know when the hole started to form and when these three workers with NPC were exposed to a high concentration of sulphuric acid vapour. Yet, the three workers with NPC were the only people who were required to work a shift schedule and stay overnight every 3 days and sleep beside the hole in the rest room. Except for sulphuric acid vapour, they were not exposed to any other known environmental chemicals. These findings indicate that exposure to sulphuric acid vapour might be highly associated with the development of NPC.

A similar working environment with long term exposure to acid, especially to sulphuric acid, among various occupational groups, and the subsequent development of aerodigestive cancer and cancers of the upper respiratory tract-such as laryngeal cancer-has been reported. ${ }^{23}$ Coggon et al showed that risk of upper aerodigestive cancer was moderately increased in those who had worked for $\geqslant 5$ years in jobs entailing exposure to sulphuric or hydrochloric acid in excess of $1 \mathrm{mg} / \mathrm{m}^{3} .^{2}$ In another survey, Steenland et al reported an excess of laryngeal cancer in steel pickling workers exposed to sulphuric acid mist with a concentration of $0.2 \mathrm{mg} / \mathrm{m}^{3}$ for about 9.5 years. ${ }^{3}$ In our study, the concentrations of ambient sulphuric acid were as high as $0.18 \mathrm{mg} / \mathrm{m}^{3}$ around the hole on the sixth floor in the telecommunication conveyance station; however, we only have the current ambient sulphuric acid concentration and we do not know how long these three workers with NPC have been exposed to sulphuric acid vapour. Therefore, comparisons between these and our results should be cautious.

As EBV infection has been proposed to be closely associated with the development of $\mathrm{NPC}^{5}$ and two of our patients had high titres of IgA antibody against EBV-VCA (1:160 and 1:1280), there is a possibility that NPC in these patients may have been induced by EBV infection. However, although positive EBV signals 
tumour cells, we found that all three NPC specimens contained EBV free tumour cells. This finding indicates that EBV infection is not the only causative factor of the development of NPC in these three cases, similar to our previous findings. ${ }^{5}$ Furthermore, the presence of EBV and SC positive cells in the sections indicates that EBV may infect the NPC tumour cells, instead of normal cells, through the endocytosis of EBV-IgA-SC complex as we previously described and possibly that EBV was not a causative factor in the induction of NPC in these patients. ${ }^{45}$

Our current study suggested that long term exposure to sulphuric acid vapour may cause NPC to develop. This is a serial case study; therefore, we cannot elucidate the causal relation between environmental exposure and cancer development. A large scale epidemiological study and a comprehensive investigation of the working environment need to be implemented. Also, we should focus on the pathogenesis of tumour transformation in response to the effect of long term exposure to acidic agents.
This research was supported in part by a research grant (DOH87-HR-710) from the National Health Research Institute and a grant (NSC86-2314-B002-281) from the National Science Council, Taipei, Taiwan, Republic of China (CTL). We thank Drs WJ Chen of Chung-Gung Memorial Hospital at Kaohsiung and SJ Lin of Kaohsiung Medical College for providing paraffin sections of two separate NPC biopsy specimens.

1 International Agency for Research on Cancer. IARC monographs on the evaluation of carcinogenic risks to humans. Vol 54. Occupational exposures to mists and vapors from strong inorganic acid and other industrial chemicals. Lyon: IARC, 1992.

2 Coggon D, Pannett B, Wield G. Upper aerodigestive cancer in battery manufacturers and steel workers exposed to mineral acid mists. Occup Environ Med 1996;53:445-9.

3 Steenland K, Schnorr T, Beaumint JJ, et al. Incidence of laryngeal cancer and exposure to acid mists. Br f Ind Med 1998:45:766-76.

4 Lin CT, Dee AN, Chen W, et al. Association of Epstein-Barr virus, human papilloma virus and human cytomegalovirus in nine nasopharyngeal carcinoma cell lines. Lab Invest 1994;71:731-6

5 Lin CT, Lin CR, Tan GK, et al. The mechanism of EpsteinBarr virus infection in nasopharyngeal carcinoma cells. $\mathrm{Am}$ 7 Pathol 1997;150:1745-56.

6 Hildesheim A, Levine PH. Etiology of nasopharyngeal carcinoma: a review. Epidemiol Rev 1993;15:466-85.

7 Lin CT, Chan WS, Hsu MM, et al. Clonal versus polygonal Epstein-Barr virus infection in nasopharyngeal carcinoma cell lines. Lab Invest 1997;76:793-8. 